\title{
Local time, annual, latitude, and seasonal variations of total electron content over
} Japan

\author{
K.-I.Oyama ${ }^{1,2,3}$, K. Noguch ${ }^{4}$ \\ ${ }^{1}$ International Center for Space Weather Study and Education, Kyushu University, Fukuoka, Japan \\ ${ }^{2}$ Institute of Plasma and Space Sciences, National Cheng Kung University, Taiwan \\ ${ }^{3}$ Coltd Asia Space Environment Research Consortium, Sagamihara, Japan \\ ${ }^{4}$ Department of Information and Computer Sciences, Nagoya Women's University, Nara Japan
}

\begin{abstract}
Total Electron Content (TEC) data are being accumulated by using about 1000 GPS receivers under the coordination of Japan Geographical Survey Institute to monitor the movement of Japanese islands which experience frequent earthquake. General pictures of diurnal, seasonal, and annual variations of TEC at three receiving stations, Okinawa (25degrees $\mathrm{N}$ ), Kokubunji (35degrees $\mathrm{N}$ ), and Wakkanai (45 degrees $\mathrm{N}$ ) have been obtained by using the data acquired in the period of January 2000 - January 2004. Seasonal variation shows two peaks in March and September which start to appear clearly in Okinawa at 08 JST (Japan Standard Time) and disappears at 04 JST. The magnitude of the two peaks is nearly the same until 22 JST and the September peak starts to reduce the magnitude from 02 JST and disappears at 06 JST. Whilst at Kagoshima and Aomori, two peaks appear between 08 JST and 16 JST. After 16 JST the September peak starts decreasing and disappears at 18 JST, which is much earlier than at Okinawa. Daytime TEC in January in low latitude is nearly equal to the TEC in July. Daytime TEC increases as solar radio flux increases. This tendency is the smallest in summer. Nighttime TEC also shows a slight increase as the solar radio flux increases.
\end{abstract}

\section{Introduction}

More than 1000 GPS receivers, which have been installed in Japan from Okinawa to Hokkaido, are as shown in Figureure 1 and GPS data which have been acquired with this unique number of GPS receivers have been used to study ionosphere. For the purpose of ionosphere studies, GPS data, which are originally obtained by Geographical Survey Institute, are processed by Kyoto University (Saito et al., 1998). However to acquire the absolute TEC value was difficult and most of the work have been done to 
study the variation of TEC. Recently Otsuka et al., (2002) developed a method to estimate the biases of both ground based GPS receivers and onboard transmitters, which makes it possible for us to draw the picture of the absolute TEC at any places over Japan.

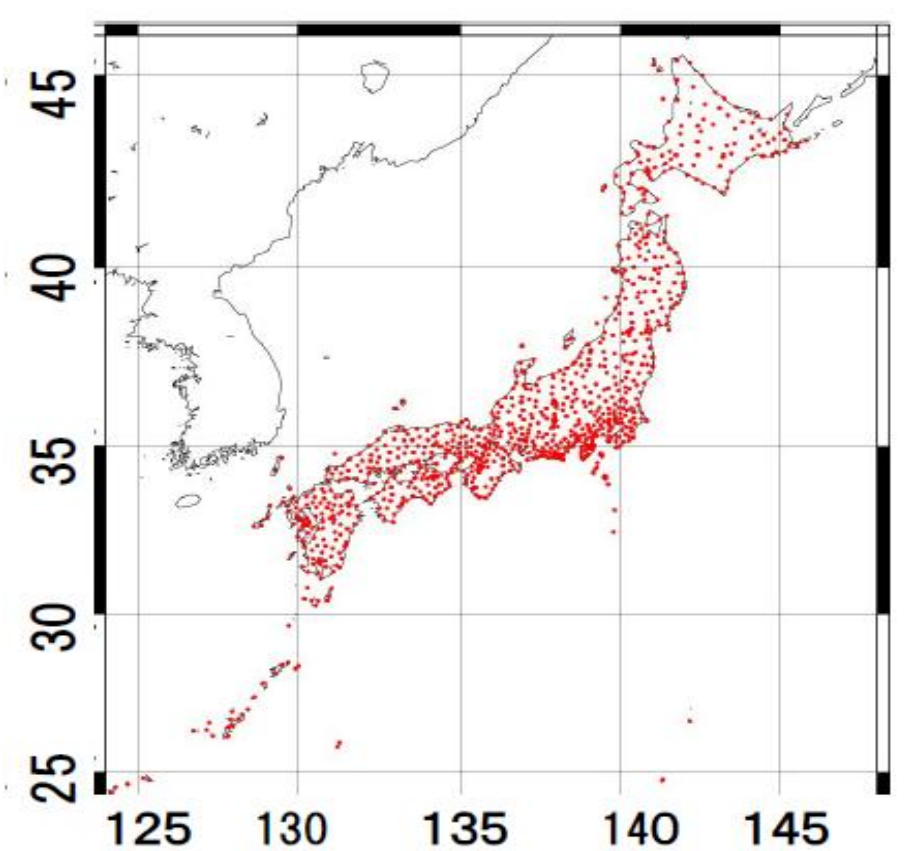

Figure 1: Location of GPS receivers, which have been installed by Japan Geographical Survey Institute. Horizontal and vertical numbers are geographic longitude and latitude in degrees.

According to plasma physics, the relation between TEC and delay time along the propagation pass of the radio wave is expressed as

$$
\begin{aligned}
\Delta \mathrm{t} & =\int(1 / \mathrm{Vg} / \mathrm{C}) \mathrm{ds} \\
& =\mathrm{e} 2 /(8 \pi 2 \mathrm{~m} \varepsilon 0 \mathrm{c} \mathrm{f} 2) \int \mathrm{nds} \\
& =1.3446 \times 10-7 \mathrm{~m} 2 / \mathrm{s} / \mathrm{f} 2 \times \mathrm{TEC}
\end{aligned}
$$

Therefore TEC of $1018 \mathrm{els} / \mathrm{m} 2$ causes $\Delta \mathrm{t}=1.34 \mathrm{~ns}$ for $10 \mathrm{GHz}$ which corresponds to $40 \mathrm{~cm}$ in distance. For the frequency of $1 \mathrm{GHz}$, which is currently used for the GPS satellite the error of the distance is $40 \mathrm{~m}$. Although the effect of the ionosphere on the positioning is removed by using two frequencies, single frequency system is still popular because two -frequency system is much more expensive. Therefore it is urgently needed for us to draw the general feature of absolute TEC in order to reduce the positioning error, which is generated as long as we use the single frequency GPS. 
In the following we present local time, monthly, annual, and seasonal variations of TEC at three stations: Okinawa (geographic latitude $25^{\circ} \mathrm{N}$ ), Kokubunji (geographic latitude $35^{\circ} \mathrm{N}$ ), and Wakkanai (geographic latitude $45^{\circ} \mathrm{N}$ ). The scientific discussions of the several TEC features, which are not fully explained, are avoided because the main purpose of the paper is to produce the average features of TEC over Japan, which has been needed for a long time by public GPS users.

\section{General behavior of TEC}

Annual variation of TEC over Japan for three stations (Okinawa, Kokubunji, and Wakkanai) is studied for 12 time zones: $0,2,4,6,8,10,12,14,16,18,20$, and 22 hours in Japanese standard time from January 2000 to December 2004. Minimum sampling rate of TEC, which we used in this paper, is 30 seconds in all stations.
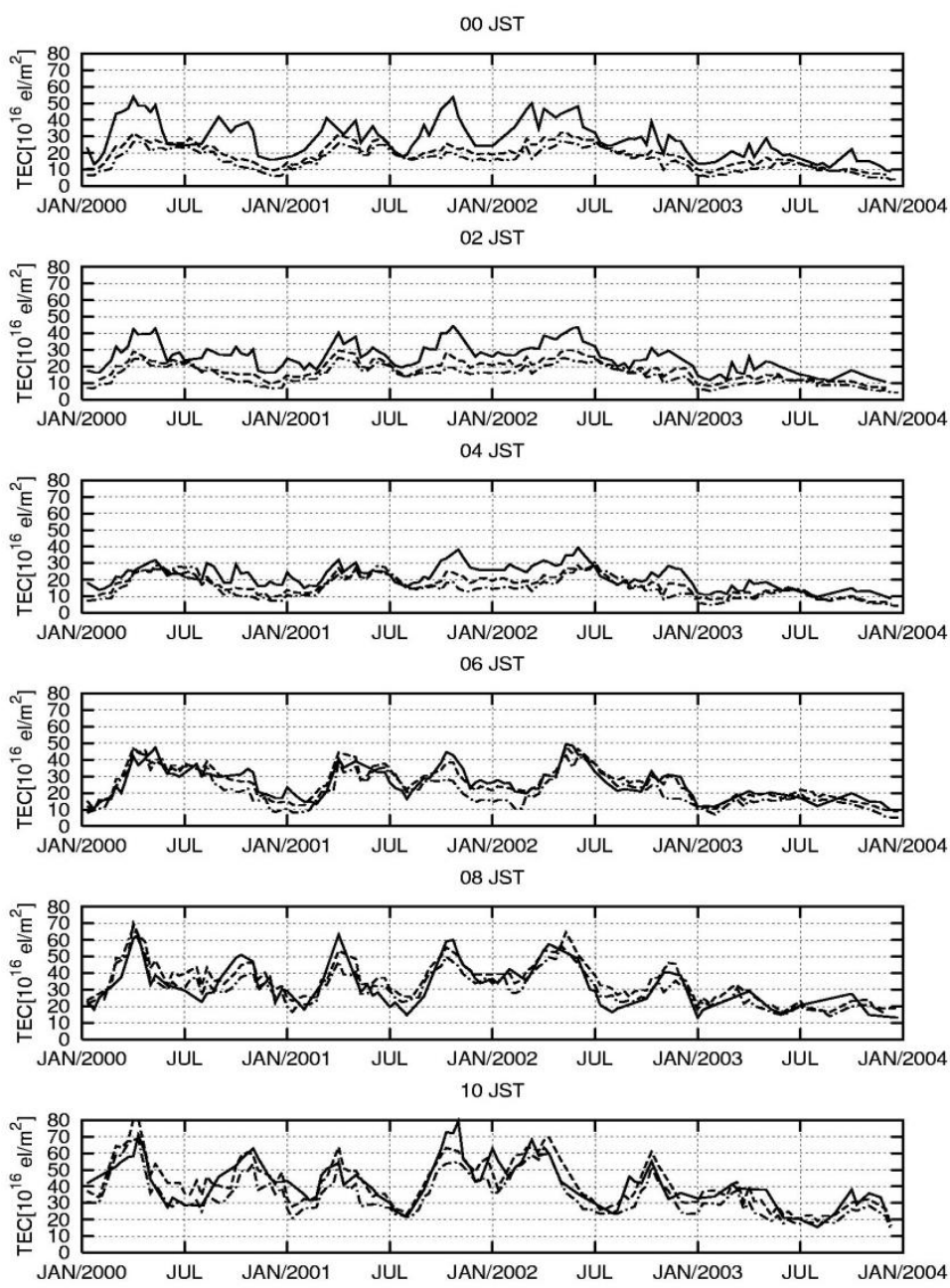

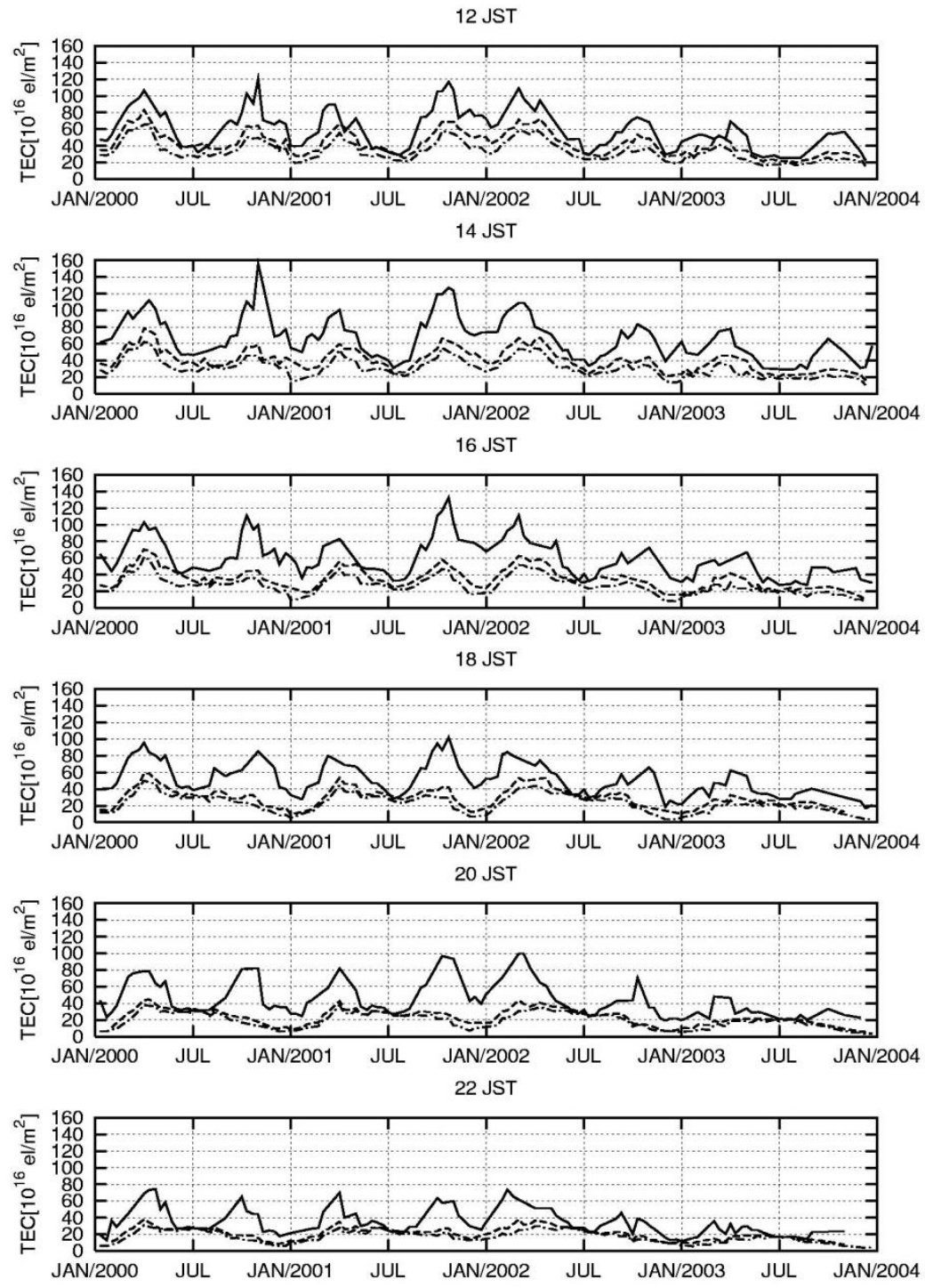

Figure 2: Annual variation of TEC over three GPS locations (Okinawa, solid line; Kokubunji, dashed line; and Wakkanai, dash-dot line) during January 2000 - January 2004. Vertical axis is TEC, which is expressed in TEC unit $\left(10^{16}\right.$ particles $\left./ \mathrm{m}^{2}\right)$, and horizontal axis is the date starting from January 2000.

The minimum TEC elements are accumulated for one hour and averaged. One hour averaged data are summed and averaged for 15 days and plotted in Figure 2 from January 2000 to January 2004. The area mesh of each stations are $1^{\circ} \times 1^{\circ}$ at Kokubunji and Wakkanai, whilst area mesh of $2^{\circ} \times 2^{\circ}$ was taken at Okinawa to have the nearly same amount of data as at other two stations. As Figure 2 shows, a latitude variation of TEC indicates that TEC reduces as the latitude increases from Okinawa to Kokubunji in all 
season and in all local time. The rate of reduction of TEC with latitude is the highest between Okinawa and Kokubunji especially during July 2001 to July 2003. The difference of TEC between Kokubunji and Wakkanai is small (Titheridge et al., 1983).

Semiannual variation of TEC shows two peaks in March and September. At Okinawa in 2000, two TEC peaks start appearing at $08 \mathrm{JST}$, and after they evolve to the maximum at $14 \mathrm{JST}$, they start reducing, and finally disappear at 02 JST. The peak values of TEC in March is about 20 TEC Unit higher than that of September at 10 JST, and September peak is higher than March TEC at 12, 14, and 16 JST. The March peak again becomes higher than September peak at 18 JST, and finally September peak vanishes at 4 JST in the morning. Whilst at Kokubunji and Wakkanai, two peaks start appearing at 08 JST, simultaneously with Okinawa. Two peaks develop to maximum value at 12 JST. September peak is lower than March peak at any time and it disappears at 16 JST and only March peak remains through the night. Peak value of September in 2001 is 30 (at 12 JST) - 50 (at 16 JST) TEC unit higher than that of March in 2001. This higher peak is partly due to the increase of solar radio flux, which occurs from August 2001 to March 2002. TEC behavior in 2002 and 2003 is similar to that of 2000. TEC reduces as the year proceeds toward 2004 due to the decreasing solar radio flux. Difference exists in the TEC values of two peaks. In 2001 the September peak at Kokubunji and Wakkanai still remains until 18 JST, whilst September peak in 2000 disappears already at 18 JST. Minimum values of TEC, which appear in January and June in Okinawa in 2000, are nearly the same. On the other hand in January 2002, the minimum value is about 10 TEC units higher than July in 2000, 2001 and 2003. Minimum values at Kokubunji and Wakkanai show about 10 TEC units in 2000, 2001 and 2003. TEC in January 2002 is 10 TEC units higher than other years, which is similar to Okinawa.

The standard deviation of TEC, which is discussed in Figure 2, is shown in Figure 3. Maximum deviation of 25 TEC units is found in 14-20 JST at Okinawa from September 2001 to March 2002, when solar activity is higher than any other time. Average deviation is about 2 TEC units during nighttime and 10 TEC units during daytime at Okinawa. The deviation reduces as the latitude increases from Kokubunji to Wakkanai, which is about 1 TEC unit (1016 els/m2). This suggests that if we can have a good model of TEC for annual variation, the error of the distance can be estimated very small. 
00 JST
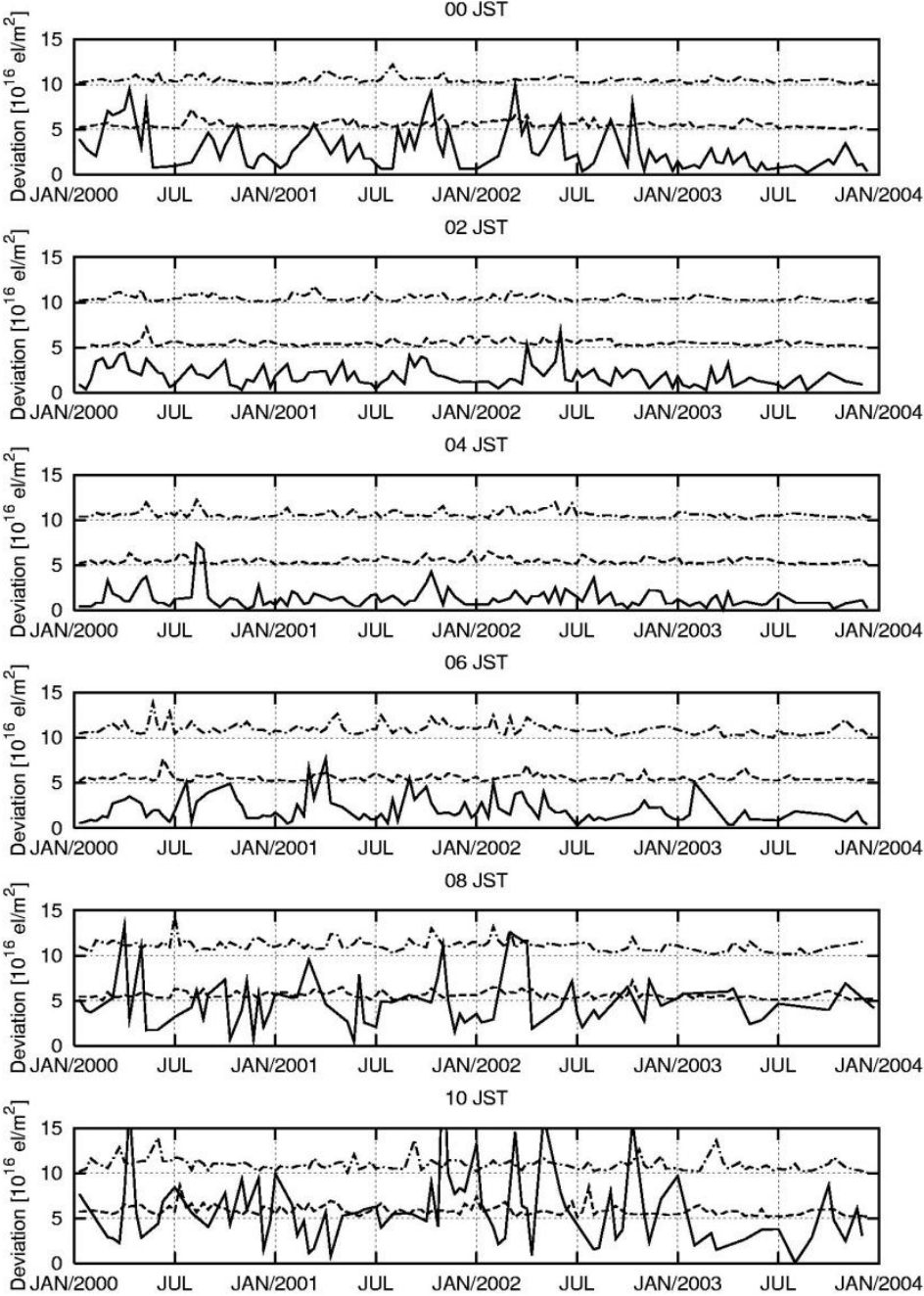

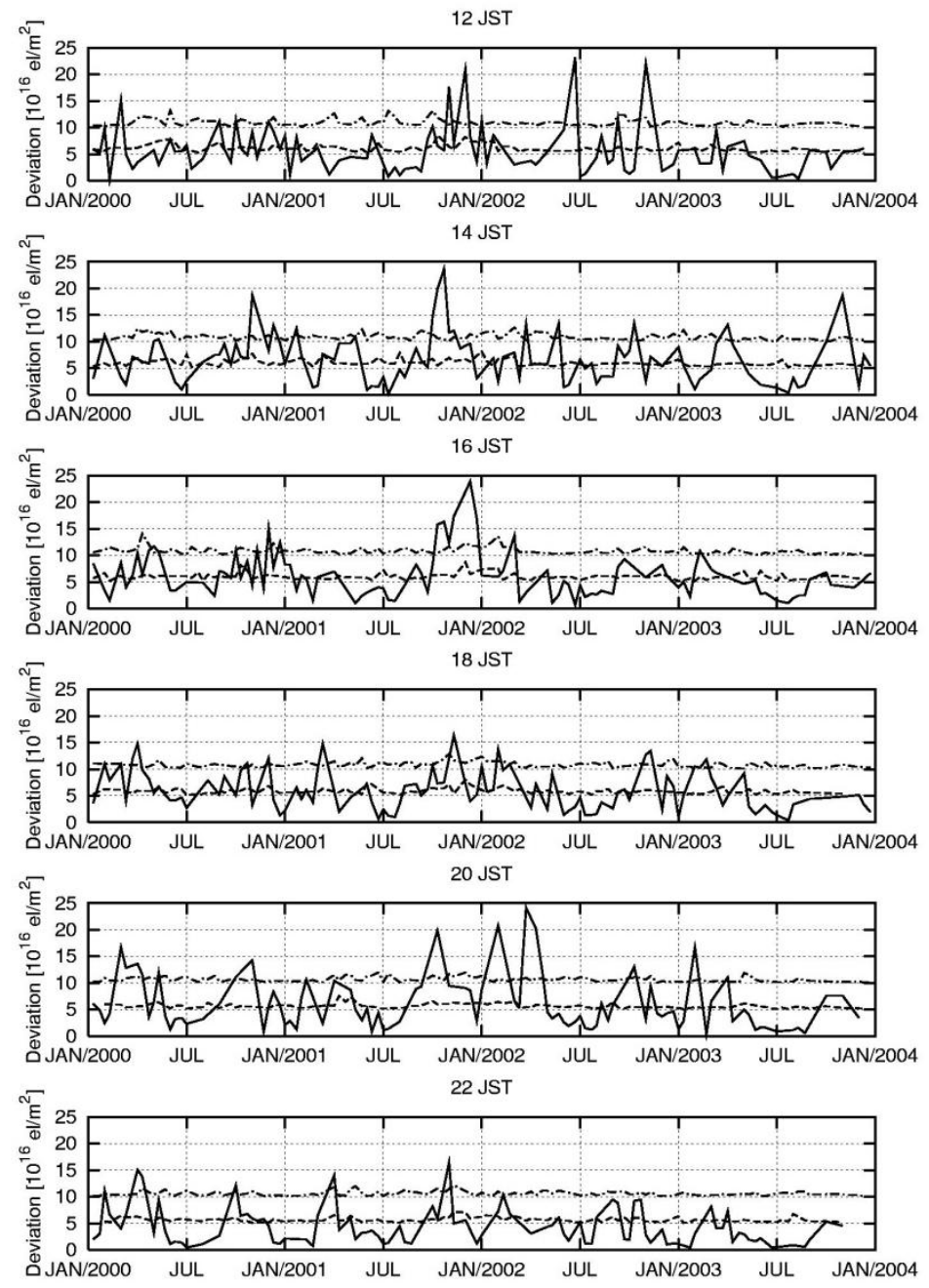

Figure 3: Standard deviation of annual TEC variations at three stations. For Kokubunji and Wakkanai, origin of TEC is shifted at 5 and 10 TEC units in the vertical axis. Solid, dashed, and dash-dotted lines are for Okinawa, Kokubunji, and Wakkanai.

In Figures 4a, b, and c, examples of solar flux dependence of TEC are shown for daytime (11-14 JST) and nighttime (01-04 JST) at three stations, Okinawa, Kokubunji, and Wakkanai. The F10.7 solar radio flux dependence of solar of TEC was grouped into four season's flux (The solar flux unit is expressed in units of 10-22 W/m2Hz). As Figure 4a for Okinawa shows, daytime TEC increases as solar flux increases in all seasons. Three colors indicate years 2000 (red), 2001 (green), and 2002 (blue). Above 180 of solar radio flux, the increase rate of TEC versus solar radio flux slows down. This tendency is the result of 
solar EUV variation which increases rather linearly with the increase of solar radio flux up to 200 and then slows down its increase above 200. In nighttime small but clear solar flux dependence is found in all seasons. Similar features are seen at other two stations as shown in Figure $4 \mathrm{~b}$ and c.
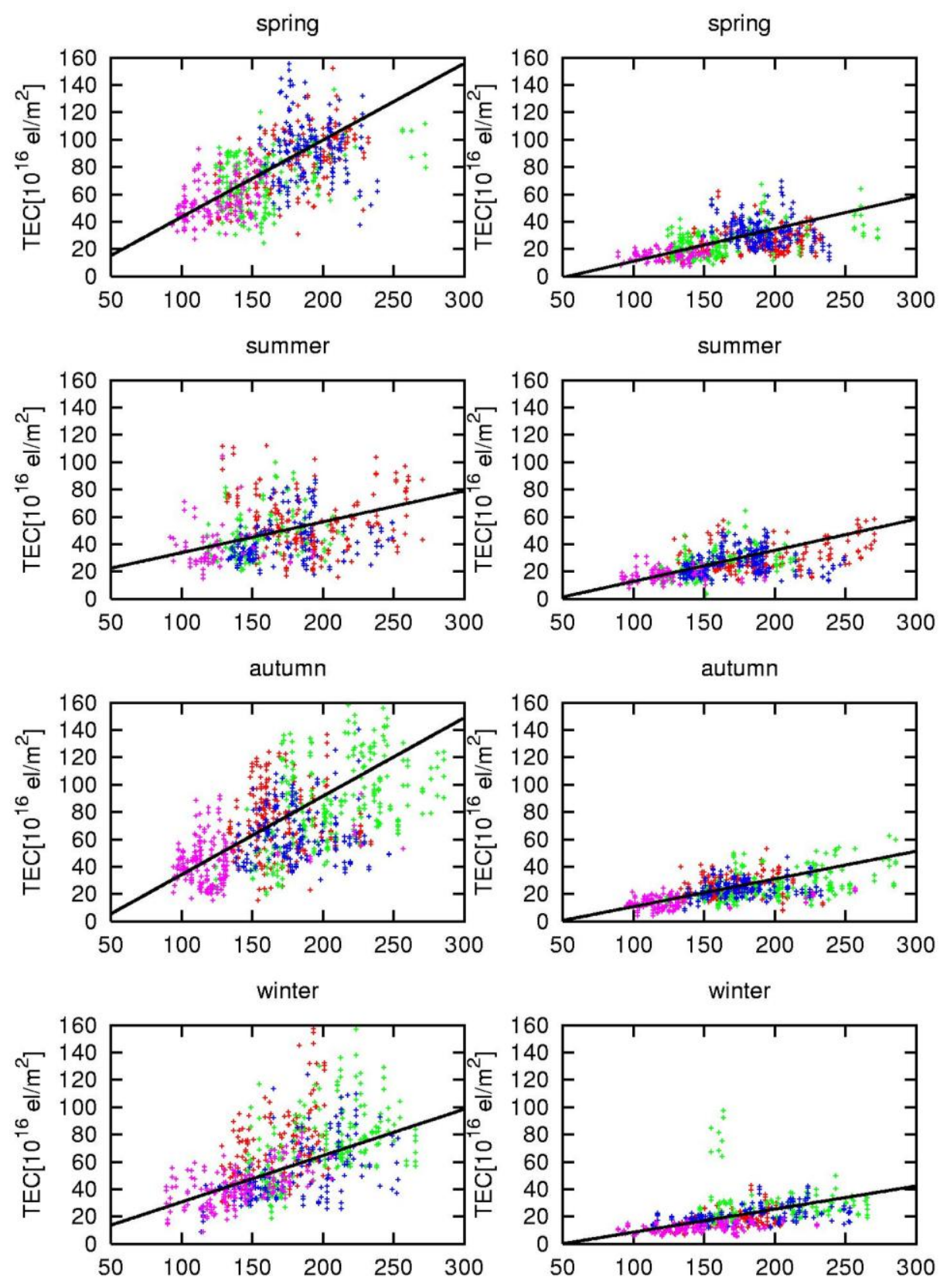

Figure 4a: Solar flux dependence of TEC at Okinawa for 4 seasons during daytime (left) and night (right).Red, green, blue, and pink dots show data from 2000, 2001, 2002, and 2003 respectively. 

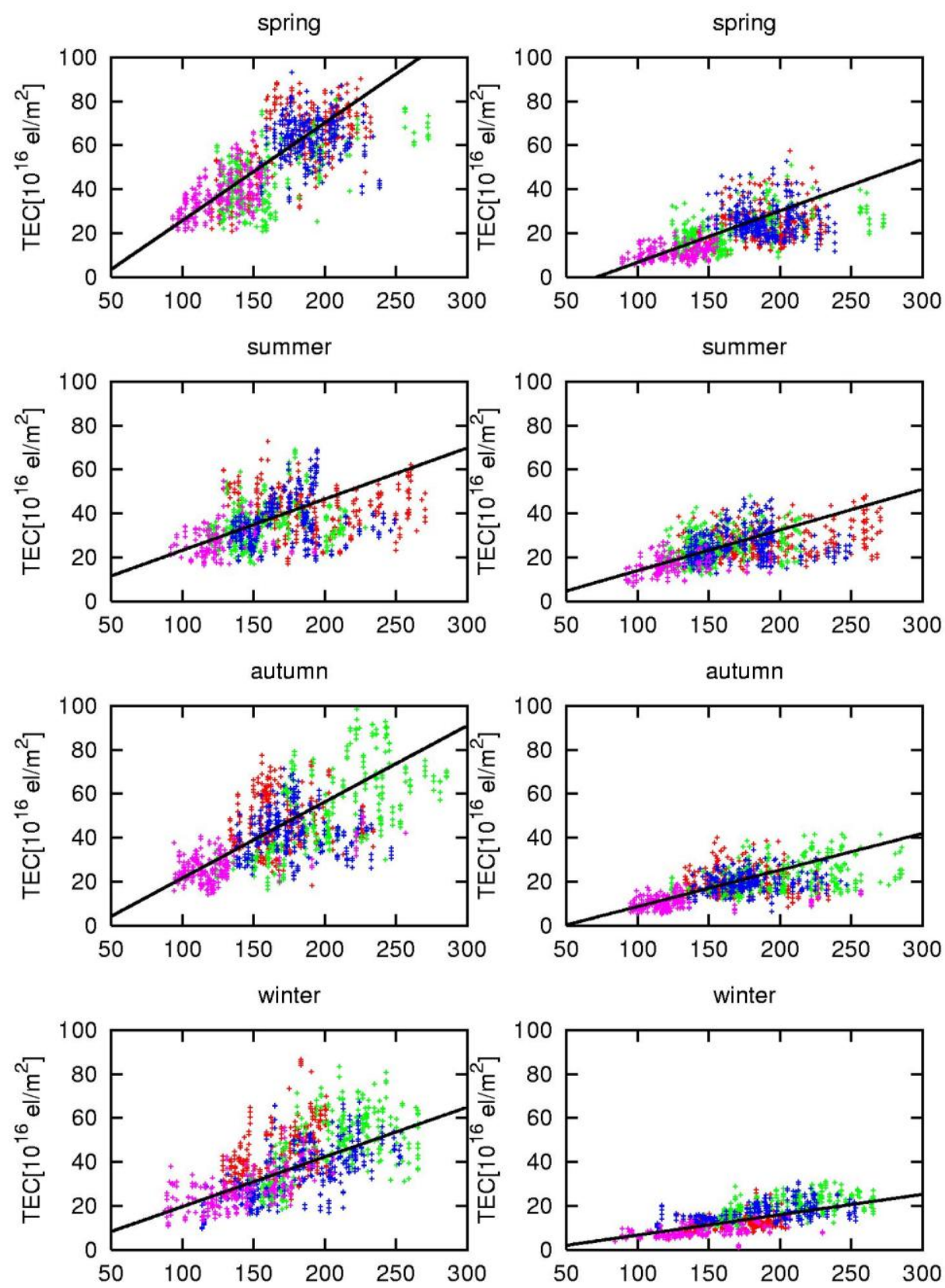

Figure 4b: Solar flux dependence of TEC at Kokubunji for 4 seasons during daytime (left) and night (right). Four groups of colors are the same as for Figure 4a. 

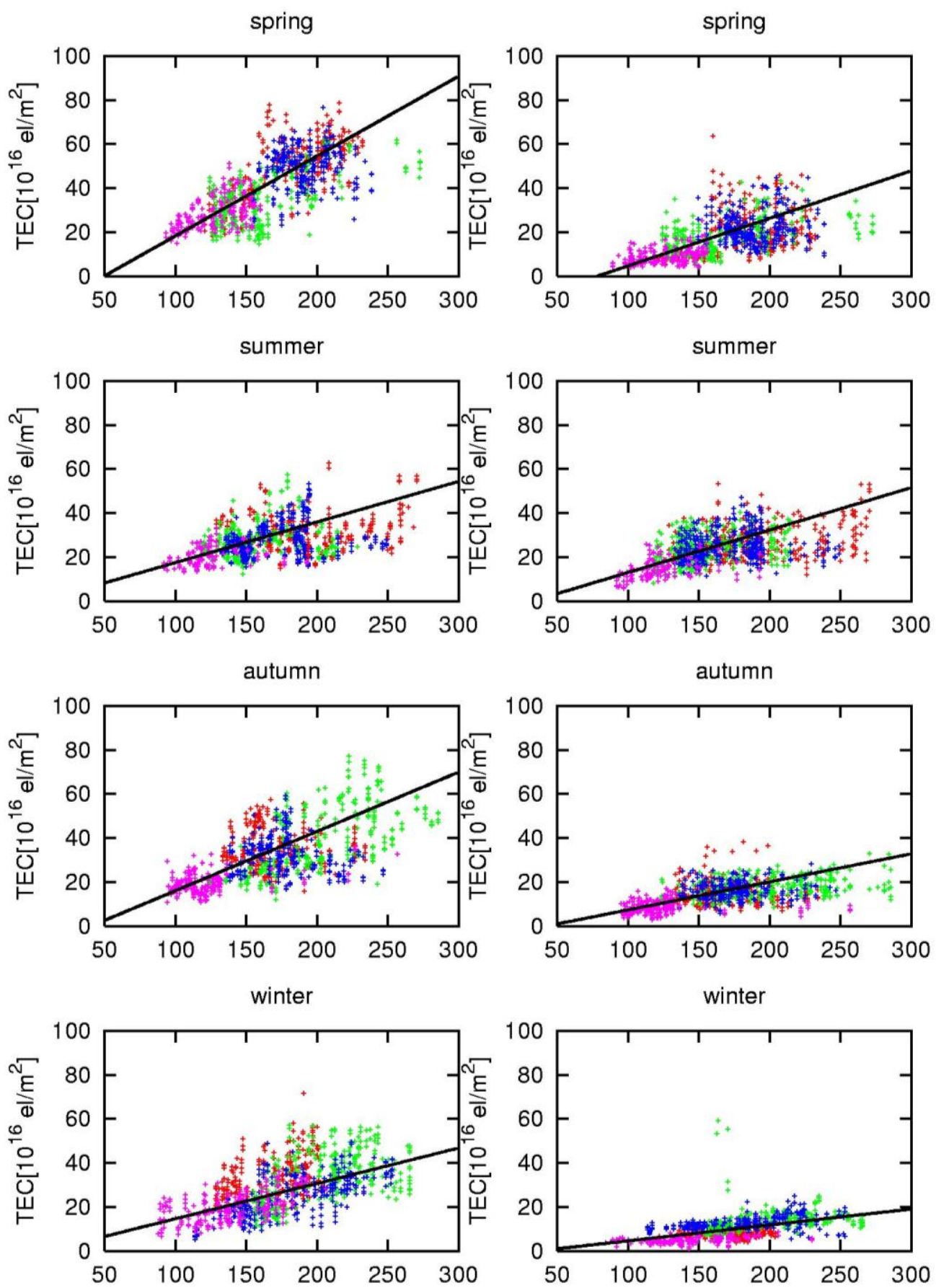

Figure 4c: Solar flux dependence of TEC at Wakkanai for 4 seasons during daytime (left) and night (right). Four groups of colored dot are the same as for Figure 4a. 


\section{Concluding Remark}

In this paper we tried to grab the general behavior of the TEC over Japan, which has not been done before. The behavior, which is presented here, is useful for the users to estimate errors of positioning over Japan. As we showed in Figure 3 the standard deviation from average TEC in Kokubunji and Wakkanai is about 1 TEC unit almost all day long and therefore the positioning error will be $40 \mathrm{~cm}$. At Okinawa maximum TEC deviation is 25 TEC units, which means that about 6 meter remains as a positioning error. We have constructed the model of the TEC, which allows users to calculate TEC at any place and at any local time over Japan. Further improvement of the modeling is still proceeding.

\section{Acknowledgements:}

We are grateful to Japan Geographical Survey Institute for supplying the original GPS data. Mr. M. Izawa plotted data.

\section{Reference}

Saito, A., S. Fukao, and S. Miyazaki, High resolution mapping of TEC perturbations with the GSI GPS network over Japan, Geophys. Res. Let. 25, 3079 -3082, 1998.

Titheridge, J. E. and M. J. Buonsanto, Annual variations in the electron content and height of the F layer in the northern and southern hemispheres, related to neutral composition, J. Atmos. Terr. Phys. 45, 683696, 1983.

Otsuka, Y., T. Ogawa, A. Saito, T. Tsugawa, S. Fukao, and S. Miyazaki, A new technique for mapping of total electron content using GPS network in Japan, Earth Planet. Space, 54, 63-70, 2002. 